\title{
TOWARDS GUIDELINES FOR DESIGN OF MOBILE SERVICES
}

\author{
Stanoevska-Slabeva, Katarina, University of St. Gallen mcm institute, Blumenbergplatz 9, \\ 9000 St. Gallen, Schweiz, katarina.stanoevska@unisg.ch \\ Hoegg, Roman, University of St. Gallen mcm institute, Blumenbergplatz 9, 9000 St. Gallen, \\ Schweiz, roman.hoegg@unisg.ch
}

\begin{abstract}
-
The paper aims to provide a contribution to the development of generic guidelines for the design of mobile data services. Using the exploratory research tool focus groups amongst other methods it examines the mobile alert service "MediAlert" and takes into account both user as well as business requirements. It's presenting first results of a longitudal research project involving a series of field trials of various mobile applications.
\end{abstract}

Keywords: Mobile Services, Business Models, Customer-Oriented Design.

\section{$1 \quad$ INTRODUCTION}

After several delays broadband mobile Internet is slowly but surely becoming a reality. More and more operators are launching 3G services in many European countries (see UMTS Forum). At the same time the number of mobile users is increasing and there is a growing substitution of fixed net communication with mobile communication. This developments rise again expectations in new mobile applications. Offering mobile data services is expected to be a profitable business in the years to come. According to a report by the Yankee Group the market for mobile content will grow to over $\$ 41$ billions in 2007 in Western Europe. Around \$ 15.5 billions will be created with services which do not belong in the peer-to-peer messaging area. (Yankee Group, 2003).

The difficulty is that nobody knows how future mobile data "killer" services will look like. The reason for that is the fact that it is often not possible to simply ask the consumer what they want, especially with respect to something that does not yet exist (Duboff and Spaeth, 2000). As a result mobile services are thrown on the market in a "Trial and Error" manner. Even though such trials provide valuable feedback about the user requirements, there is no systematic collection of experiences into generic guidelines for the design of mobile data services (see for example Reichold et al. 2004). Another approach to assess user requirements for mobile services is by way of extensive field trials of innovative applications, which simulate real life usage situations as authentic as possible. Examples of such trials are those conducted by Kaasinen for location-based services and guides (Kaasinen 2003; Kaasinen 2004), the trials conducted by Aalto et al. (2004) related to push based location-aware mobile advertising systems, the trials of video streaming applications described by Brodt and Heitmann (2004), to name a view. Even though such filed trials provide valuable results in particular for the specific applications under evaluation, they have several limitations with respect to the scalability of the results towards generic guidelines for mobile application. The evaluation concentrates in many cases on a specific aspect of mobile application as for example usability. As a result even available generic guidelines are focused on a specific aspect as for instance the usability guidelines proposed by (Gong and Tarasewich, 2004), (Tarasweich 2003) or remain on a general level as provided by (Jarvenpaar et al. 2003). Another constraint of the studies is the lack of consideration for aspects that are related to business models for mobile application, i.e. factors related to commercial success of mobile application. For example an application might be considered as easy to use and nicely designed, but users would not be willing to pay for it. As a consequence, there are in general no systematic overall guidelines 
how to design mobile data services and what other critical factors then user requirements affect the commercial success of such application.

This paper provides a contribution to the development of generic guidelines by presenting first results of a longitudal research project involving a series of field trials of various mobile applications. Based on a field trial of the mobile alert service "MediAlert", a first version of guidelines for the design of mobile application is provided, which considers both user and business requirements. The results presented here will be validated, tested and improved with subsequent field trials of other mobile application as video streaming, mobile services for special events and others.

The content of the paper is structured as follows: Section two contains a short description of the evaluated application "MediAlert". In section three the evaluation approach is described and section four contains a summary of evaluation results. Section five concludes the paper with a first version of guidelines for the design of mobile services.

\section{THE "MEDIALERT" SERVICE}

The "MediAlert" service was developed within an international project funded by the European Commission (Kasper et al., 2003). The "MediAlert" service collects information about newly published books from available online information sources as for example publishers' web pages and provides information on newly published books in form of customized summaries via a variety of access devices. Users can access the service using a WAP enabled mobile phone, PDA, the world wide web (emulating the WAP as well as the PDA interface) or E-Mail.

In order to use the service the user needs to register through an online registration portal. In the registration process which is done via a web interface each user needs to define three profiles:

- User Profile - Containing their name, address, telephone number, etc.

- Access Profile - Defining their way of accessing the system. Available options are PDA, E-Mail, WAP or Web.

- Service Profile - Defining the book topics the users are interested in. The user can chose from different book categories such as e.g. "Film", "Music", "Cooking", etc. In addition to that users can set keywords to further filter the information (e.g. books on film that contain the word "horror"). In the service profile users also state how often they want to receive alerts (via E-Mail or SMS) that inform them about newly published books that match their profile. Optionally the user can chose a target language in which the relevant information is translated.

The profile information provided by the user is applied by the service for an automatical personalized search for information on new published books available in various online information sources. Thereby the information is processed through three steps (c.f. 1) (for more details see (Kasper et al. 2003):

- Acquisition

- Transformation

- Distribution

In the acquisition step information is automatically acquired from sources such as databases, the Web, as well as other specified sources. A mobile agent is used to visit relevant data sources, check for new documents in right languages, recognize the structure of the document, classify the documents, and bring them back, if they turn out to be relevant. 


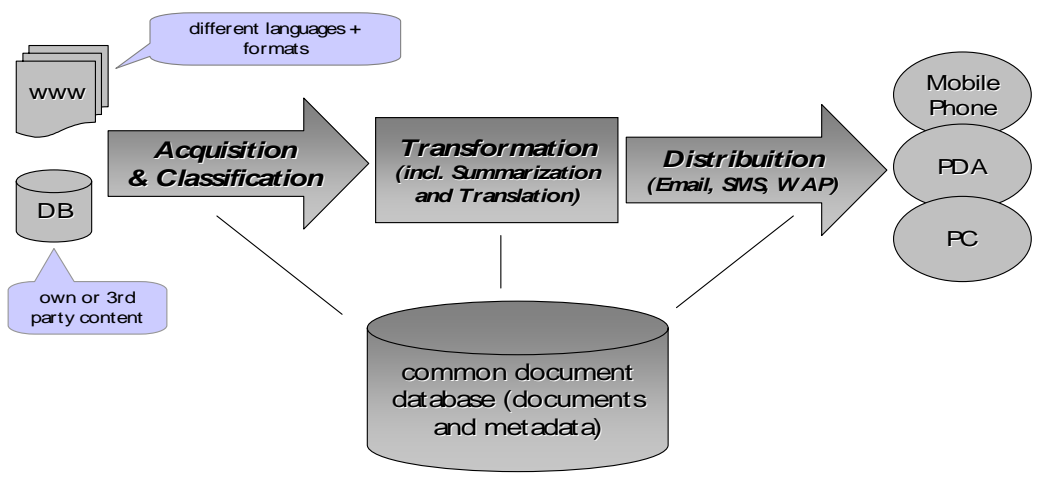

Figure 1: $\quad$ Architecture of the "MediAlert" service

In the transformation step relevant documents are transformed so that they match the output criteria. Dimensions of the transformation process are: summarization, classification, and translation. The original information is first automatically summarized into summaries with different length suitable for specific output devices. Examples of "MediAlert" summaries are given in fig. 2.

\section{Full summary:}

Cokie Roberts's number one New York Times bestseller, We Are Our Mothers' Daughters, examined the nature of women's roles throughout history and led USA Today to praise her as a "custodian of time-honored values."

Her second bestseller, From This Day Forward, written with her husband, Steve Roberts, described American marriages throughout history, including the romance of John and Abigail Adams.

Now Roberts returns with Founding Mothers, an intimate and illuminating look at the fervently patriotic and passionate women whose tireless pursuits on behalf of their families -- and their country -- proved just as crucial to the forging of a new nation as the rebellion that established it.

\section{Short summary:}

Cokie Roberts's number one New York Times bestseller, We Are Our Mothers' Daughters, examined the nature of women's roles throughout history and led USA Today to praise her as a "custodian of time-honored values."

Now Roberts returns with Founding Mothers, an intimate and illuminating look at the fervently patriotic and passionate women whose tireless pursuits on behalf of their families -- and their country -- proved just as crucial to the forging of a new nation as the rebellion that established it.

\section{Figure 2: $\quad$ Examples of "MediAlert" Summaries}

Apart from summaries of the content, "MediAlert" also extracts additional relevant information about the book. An example of such information is given in figure 3 .

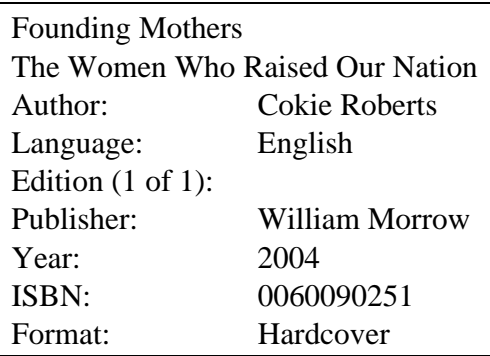

Figure 3: $\quad$ Examples of "MediAlert" meta data for each relevant document 
After the documents are summarized they are classified into the different book categories (an example is provided in figure 4 below:

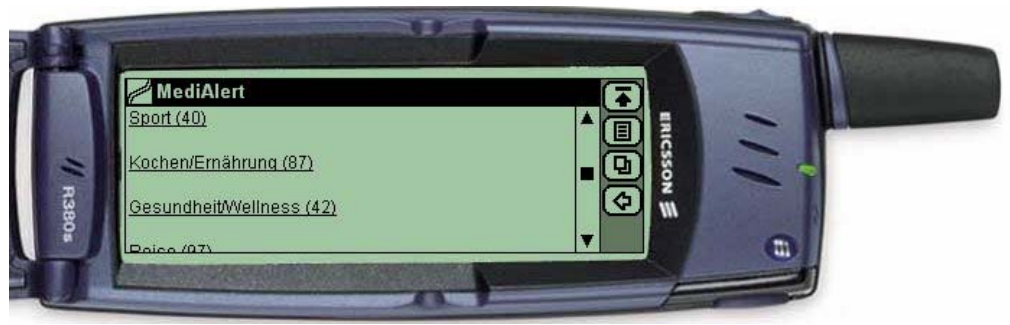

Figure 4: $\quad$ Browsing the MediAlert Archive (WAP)

Finally, the available information can also be translated into a target language chosen by the user. The system supports English, German and Italian. The transformation layer applies the necessary steps and makes the documents ready for delivery.

In the distribution step the content is rendered and sent to the service subscribers, in due time, and in due format accordingly to the specified end devices. Target devices are: PC (using email), PDA and mobiles (using SMS and WAP). When using SMS or Email as distribution channels the information is pushed to the users. This way the user instantly receives all new information acquired by the "MediAlert" system.

When using WAP however (on a mobile phone or a PDA) a pull service is implemented. Via the registration portal users can configure a notification email / SMS, which will alert them when new information has arrived. Thus, only short alert messages about newly found information are sent. If a user wants more information she/he can download it from the server using a PDA or Smart Phone. This way users only download what is of interest to them and don't have their inboxes and device memories cluttered with large messages. "MediAlert" reduces the needed memory space on the mobile device further by storing previously found information in an archive for 30 days. A screenshot of the archive is given in picture 5 below:

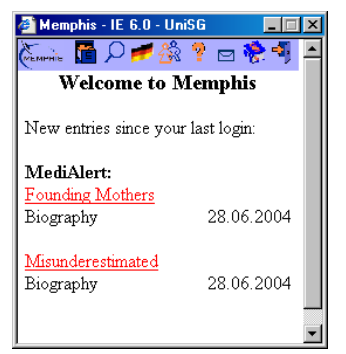

Figure 5: Screenshot of a personal "MediAlert" archive on a PDA

The archive keeps track of what each user has already read. This support saves the user from having to tediously search for new information.

In summary "MediAlert" is a service that offers instant and easy access to up to date information via mobile devices or email. Since all users have individual profiles which they can customize via the web based registration portal only information relevant to each one is being transmitted. There is no need to search several individual sources, as one site collects all information for the user. This is especially convenient when using mobile devices with limited screen size, bandwidth, computing power and input facilities. Once the profile is set up the user doesn't have to manually search, type or filter anything. All the desired information is collected and categorized in one place which can be reached within a few clicks. 
Another important factor for the user is that she/he has the choice between push and pull services. Even though irrelevant information has been filtered out beforehand users don't want to have their inboxes cluttered up with messages. By choosing a pull service, all the user gets delivered automatically are alerts about new information that has been collected by the acquisition layer. How often these alerts are sent is up to the user's preferences. This way the user accesses the "MediAlert" services when she/he wants to.

\section{RESEARCH DESIGN OF THE "MEDIALERT" EVALUATION}

\subsection{General Overview of the Research Design}

The "MediAlert" service was tested in a field trial. The application was available for test users during three weeks. The main goal of the evaluation was to get feedback with respect to both user requirements upon the application and related to feasible business models. Given this goal the evaluation was designed in such a manner as to provide feedback to main components of business models. Thereby one of the most cited definition for business models proposed by Timmers (1998) was used as structuring foundation for the evaluation. According to Timmers, a business model is "... an architecture for the products, services and information flows, including a description of various business actors and their roles, a description of the potential benefits for the various business actor, and a description of the sources of revenues." (Timmers 1998). Given this the evaluation was structured along the following main components of a business model (c.f. 6): value chain and business systems for mobile application, product and its features and customers. In addition the main flows of financial resources and services were considered.

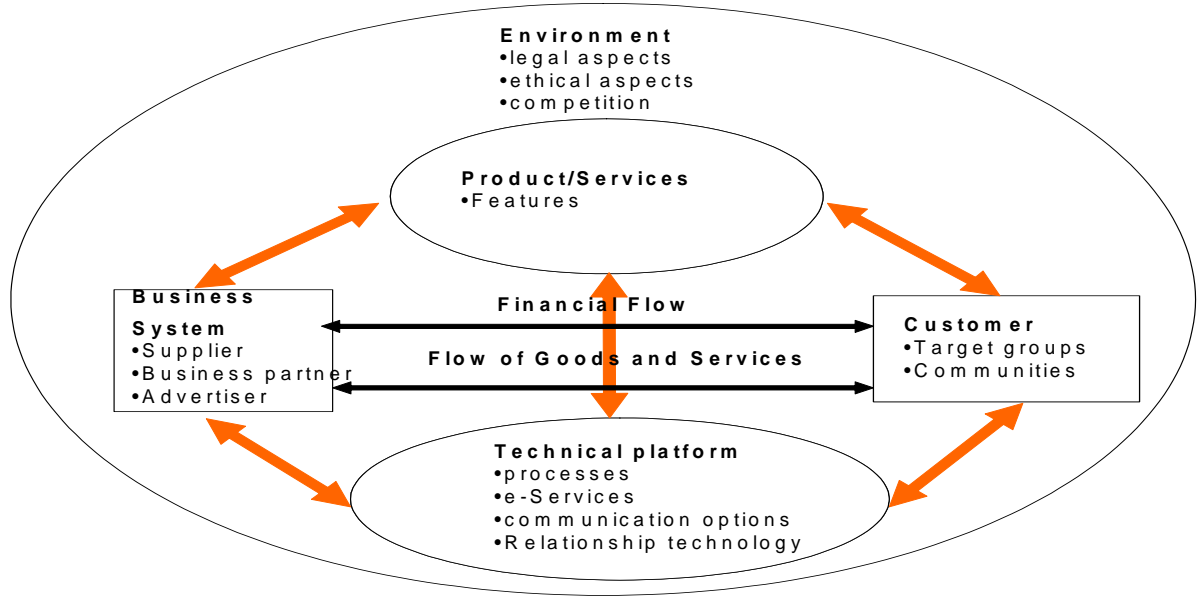

Figure 6: $\quad$ Components of Business Models

Based on the above general definition for business models, questions that were addressed during the evaluation were:

- Who are the potential users and what are the user requirements upon mobile services as "MediAlert"?

- Is there a market for services like "MediAlert"?

- How should a business model for services as "MediAlert" be designed with respect to payment models, value chain and similar in order to assure commercial success?

- What other services would be of interest based on the software system providing the "MediAlert" service? 
Due to the multitude of questions a set of three methods was required: qualitative research based on focus groups, quantitative research based on structured online surveys and expert interviews. The three research methods had an overlapping part related to assessment of user requirements and some specific parts related to different business model components. The expert interviews were designed to provide insights into the necessary business system for mobile application and to derive out of it main financial and service flows. In addition they provided insights into possible income models. The structured online survey was addressing mainly features of the "MediAlert" service and was answered by users, who used the service in a real life setting within three weeks. The focus groups were used to assess user requirements upon the "MediAlert" service and to analyze the attitude and experiences of users with mobile application in general.

Interviews were conducted with three experts in the area of mobile business and 30 persons filled in an online questionnaire after having tested the system for a period of 3 weeks. The information collected from these two inquiries focused heavily and specifically on the "MediAlert" service. The results from the third study with focus groups have a much larger focus. As this paper aims to drawing conclusions that are generalizable for different types of mobile services and focuses more on the mobile user than on a specific application, it solely examines the knowledge gained trough the focus groups sessions.

\subsection{General Overview of the Focus Group Method}

As an exploratory research tool focus groups are often used to gain insights and ideas. In a focus group session a small number of participants talk about a topic of interest. The discussion is guided by a moderator who attempts to follow a rough outline of issues that need to be considered. At the same time comments made by each person are included in the group's discussion. (Churchil and Iacobucci, 2002)

Focus Groups have proven their productivity for the following purposes (Churchil and Iacobucci 2002):

- To generate hypotheses that can be further tested quantitavely

- To generate information helpful in structuring consumer questionnaires

- To provide overall background information on a product

- To secure impressions on new product concepts

The participants of the groups are relatively homogenous to minimize differences in perceptions, experiences and verbal skills. To nevertheless gain a wide spectrum of insights multiple group sessions are held (Churchil and Iacobucci 2002)

One of the main advantages of focus groups is that they allow for serendipity. During the focus group discussion ideas can drop "out of the blue". Further, an idea of an individual can trigger responses from other participants and thereby develop further. Compared to being interviewed alone, many participants feel more secure in a group. Ideas they expose don't have to be defended or elaborated by them. As a consequence responses are often more spontaneous and less conventional (Churchil and Iacobucci 2002) Group interaction is therefore explicitly wanted. It generates data and insights that would otherwise be difficult to get to. (Flick 2002)

Focus groups do however also have weaknesses. It must be considered that the discussion and also its results are heavily influenced by the moderator and his or her provided direction. (Churchil and Iacobucci 2002) The extent of influence of the moderator depends on the degree of structure of the focus group. Approaches to focus groups sessions can be more or less structured. The more structured the focus group is, the higher the potential for the moderator to influence the results (Gubrium and Holstein 2002). 
Participants: The participants in the focus groups were selected based on two criteria: their potential interest for the "MediAlert" service and their previous experienced with mobile services and mobile end devices. They all have considerable computing knowledge as well as have experienced with new media products. The reason for this selection was to shorten the time needed to explain the underlying service and to increase the chance of having a fruitful brain storming session.

The participants of the focus group sessions were:

- 8 PhD Students (3 female, 5 male, 25-30 years old)

- 4 students at the bachelor and master level (4 male, 20-25 years old)

- 2 former students (2 male, 26 and 29 years)

The participants were divided into three groups depending on their previous experience with mobile application and different end devices. One group consisted of typical first movers, i.e. experienced users of mobile services with mobile phones. The second group consisted of users of PDAs and a third group consisted of users with little or no experience with mobile services or PDAs.

Structure of the focus group questions: The focus groups were loosely structured, based on the guidelines suggested by Krueger, R.A. (1998). The moderator tried to ask all questions but did not interrupt the discussion if it took another direction. The structure of the focus groups questions was as follows:

- Opening Questions - Participants got acquainted through welcoming and introductory questions.

- Testing The System - The participants were given the chance to test the system on real hardware for about 10 minutes.

- Introductory Questions - The discussion started with open ended questions how the participants understand the phenomenon under investigation. The questions asked for an overview. For example: When you hear the words "mobile information service", what comes to mind?

- Transition Questions - were used to move smoothly and seamlessly into the key questions and to help participants to envision the topic in a broader scope. These questions had more depth than introductory questions. For instance: How did immediate information change your life?

- Key Questions - are related to areas of central concern in the study. The "MediAlert" evaluation was guided by the following questions:

o What kind of mobile information services do you use at the moment? Why do you use them? What distinguishes them from other services?

o What distinguishes "MediAlert" from other information services?

o What kind of mobile information services are you missing today? And do you think "MediAlert" could offer such services? If not, what would have to be changed? What would be an ideal service?

o Do you have suggestions on what else could be done with the "MediAlert" technology?

o Suppose there was a "MediAlert" service like the one you saw today. What content would you be interested in? Would you be willing to pay for such a service?

- Ending Questions - enable participants to reflect on previous comments. For example: Is there something we should have talked about but didn't?

Evaluation Procedure: There were 3 focus group sessions conducted, taking into account the participants individual familiarity with mobile technologies. In the first session all users had experience with WAP mobile phones, in the second one they were experienced PDA users. Participants of the third group neither had any experience with WAP nor with PDAs. 
The focus group research provided the insights with respect to customers of mobile services in general and the specific mobile service "MediAlert" in particular. The results are described in the following subsections.

\subsection{Evaluation Results with Respect to Customers of Mobile Services}

The discussion at the beginning of the focus group around the more generic questions provided insights into how users experience mobile services and the impact of the mobile phones:

The usage of mobile phones has strong social impact. The mobile phone and mobile services have become an important part of social relationships and other aspects of the organization of ones private as well as professional life and social contacts and networks. Mobile technology has made everything faster and more dynamic. The fact that mobile devices provide access to immediate information seems to have an influence on all participants' lives. On the one side there is an agreement that it is nice to have access to information (e.g. information on free flats). This saves time but since everybody now has this information everything seems to speed up. More and more options are opened up (e.g. contact with people from around the world) but this also means that fewer things are being organized in advance and people are expected to react spontaneously and flexibly.

In summary, the usage of mobile phones results in a new mobile lifestyle. The following quote of one of the focus group participants illustrates the changes in lifestyle:

Quote (change of lifestyle through mobile communication): "My lifestyle has changed in that I and my friends are getting lazier. We organize less. We have our mobile phones and know we can reach each other anyway. One is more flexible in the way that one has faster access to information that may change priorities. Maybe one had specific plans for a night out when friends call and say that there's something going on in another place, so one goes there instead. Or one has planned to go home and get a call that there is some action somewhere. My feeling is that people need to be more spontaneous nowadays. People expect that and I think this has changed my life." ${ }^{1}$

Another important result of the focus groups is the reveal of the differences of user experiences. As the participants of each group had different levels of experience with mobile devices and services an inter group comparison shows some additional information. (Group $1=W A P$, Group $2=P D A$, Group3 = no experience)

The differences start in the groups' definitions of what "mobile information services" are. Group 1 stressed that a mobile information service has to focus on the added value, provided by mobile access. They compared the "MediAlert" service with previous experiences with other services as for example TopPreise.ch, the schedule of the Swiss railway system SBB.ch or simply access to email accounts. Based on their previous experience group 1 was able to forecast and formulate the user requirements months or maybe even years before other users can (Springer et. al. 2004). Group 2 on the other hand can imagine any information service to be used mobile. For them, it is only important that they have information whenever and wherever they want it. Group 3 had no clear vision of what defines a "mobile information service". Since group 1 was the only group which had actual experience with mobile services (none of the PDA users had ever used a PDA to access the internet) there were considerable differences in what was expected from a mobile information services.

\footnotetext{
1 "Mein Lebensstil hat sich insofern verändert, als dass ich merke, dass ich und Kollegen von mir einfach fauler werden. Wir organisieren weniger, wir gehen darauf los. Wir haben unsere Handies, wir erreichen uns sowieso. (...) Man wird einfach flexibler zu einem Teil, weil man schneller zu Informationen gelangt, die dann plötzlich die Prioritäten umstellen. (...) Man hat vielleicht irgendwo im Ausgang was geplant und dann plötzlich meinen Kollegen da ist was los und dann geht man dorthin oder man hat geplant jetzt nach hause zu gehen, da kriegt man nen Anruf: "Dort läuft noch was", dann geht man dort hin. (...) Ich hab das Gefühl, man muss immer spontaner werden. Die Leute erwarten das und ich denke insofern hat das mein Leben auch verändert."
} 
These findings related to the differences of users reveal both that there is a clear distinction among first movers and the masses of mobile phone users and the fact that the increasing number of mobile phone users does not automatically mean an increase in mobile service users. It will take time to convert mobile voice users to mobile data users and the realistic market potential for mobile services can not be deduced automatically from the number of mobile phone users. It will depend on factors as innovativeness of the user, his attitude to data services in general, the end devices he is using, and similar.

\subsection{Evaluation Results with Respect to the Service "MediAlert"}

The focus groups provided feedback to specific features of the service in particular, to the service in general, as well as to some aspects related to financial models. The following features of the service were discussed in more detail:

Registration: It was not obvious to the testers why they had to register online for a service they wanted to use on a mobile device. It was also very tedious for them to enter so much information. Participants from all three focus groups would have preferred a simpler and shorter registration process. Other information services they had tested in the past e. g. only needed an e-mail address.

Quote (Registration): " Google Alert - I think that's pretty ingenious (...) It uses some kind of profile as well. But it's as simple as ingenious. Without a username one just enters the combination of terms one is interested in, enter an e-mail address and that's it. Very simple. If it would have said that there is a registration process that expands over three pages the inhibition threshold would be bigger. (...) Something similar could be done by "MediAlert"." ${ }^{2}$

Participants from all three groups were worried about privacy issues. Many did not like to give as much information as they had to register to the "MediAlert" service. Some even said that this point alone would have prevented them from registering to the service if they had not done it for testing purposes.

Quote (Registration process): "Well, I have to admit I always feel a little uncomfortable if I have to give away so much information about myself. (...) I'm a little skeptic about that. ${ }^{3}$

Summaries: The summaries that were created automatically by the service were considered of good quality and very useful.

Classification: The participants of all groups liked the automatic classification and structuring of the content into different categories. The classification provided support for immediate orientation within the available information and enabled a fast navigation and choice of the most important information.

Archive: All participants liked the idea of a personal archive in general. However, one of the main points that all groups agreed on was that there should be more control over the content in the archive. The number of entries presented was too big and the automatical deletion of all content after 30 days was not considered as user friendly. Users also missed familiar features such as functions that made visible which entries they had already read. With additional functionalities the system could be turned into a personal information system which could conveniently be accessed wherever and whenever needed (e.g. in the bookstore).

Quality of content: Focus group participants of all three groups missed some sort of indication on the quality of the information they received. Not only was it unclear where the book summaries were from

\footnotetext{
2 "Google Alert - den find ich irgendwo ziemlich genial (...) Das ist auch eine Art Profil. Dort ist's aber sehr simpel, wie genial gelöst, ohne gross den Benutzernamen anzugeben, gibt man einfach die Suchkombination der Wörter ein, gibt die Emailadresse an und fertig. Sehr simpel. Wenn jetzt zum Beispiel bei Google gestanden wäre, ja, registrieren über drei Seiten, dann ist auch die Hemmschwelle relativ grösser. (...) Ähnlich könnte man das auch hier lösen."

3 "Also ich muss auch sagen, ich find's immer so ein bisschen unangenehm, wenn ich zuviel von mir preisgebe (...) ich stehe dem Ganzen auch ein bisschen skeptisch gegenüber."
} 
the summaries also delivered no information on the quality of the book. Some sort of rating (e.g. with stars or reviews from other users) would have been welcomed.

Financial Aspects: None of the participants was willing to pay for a service like "MediAlert". All thought that a service like this should be paid by advertisements or sponsored by the content provider. Alternatively the provider could receive a share of what the user pays for the data traffic the service created. The user however should not be aware that she/he pays for the service. There are just too many good, free services available that deliver the same kind of information. Given the choice among various subscription models, users would prefer a model that allows payment only for used services and supports spontaneous usage. Therefore, longitude subscription models as a flat fee subscription per year were disliked.

\section{Comments to the "MediAlert" service in general:}

When asked about the " MediAlert" service all groups agreed that there is no real advantage of having access to book information on a mobile device in the form offered. In their eyes this information is neither "time critical", which would be an important factor for them, nor supports spontaneity and flexibility. Free web services such as Amazon.com sufficiently satisfy all participants' needs for information on new books. Another problem for many was the fact that there was no source given on where the information is coming from. They all agreed that there wasn't enough information on the books. Some would have liked a picture of the cover, some links to further information or even direct access to the book.

Participants from all three groups liked the fact that "MediAlert" allows for access to the same information via a variety of devices and channels. This way none of the users would have to change personal habits.

Despite of some interesting features as the archive, the automatic summaries, the classification of content as well as the possibility to search over several information sources over one application, the current version of the "MediAlert" service could not fulfill the needs of the users. It was too complicated and did not offer much additional value to what other, free information services offer already. Test users however see potential in using "MediAlert" as some sort of "Personal Information Tool" that works as a mobile search engine as well as a personal archive. At the moment there are no mobile search engines available that work in a way that is satisfying for the end users. What is needed is something that needs very few clicks and that offers few, but high quality results. The results would have to be linked to other services (e.g. giving the user the option to buy the book directly).

The participants from all three groups had at least some ideas on how to improve the "MediAlert" service. However, the WAP experienced participants from group 1, who where the only group with experience with mobile services apart from "MediaAlert", stated their visions much clearer. While the other two groups gave rather vague desires for future services, group one formulated specific features they wanted to see. All three groups shared the opinion that the "MediAlert" services should be combined with some kind of location based features. The content should be something which is time critical or specifically designed for traveling people (e.g. Issue Management, Financial News, anything that has to do with leisure or public transport).

\section{TOWARDS GUIDELINES FOR THE DESIGN OF MOBILE SERVICES}

The field trial of the application and in particular the focus group research provided first results that can be generalized towards guidelines for the design of mobile services. The results of the focus groups provided insights about the mobile customer, mobile products and financial aspects. Out of the results the following first general conclusion can be drawn: 
Mobile Customers: Extensive use of mobile phones and accessibility of information results is a new mobile lifestyle, that has to be kept in mind when designing mobile data services (see also Jarvenpaa 2003 and May 2001). Paul May (2001) describes the possibilities that mobile (data) communication enables as "a strange kind of liberty". At the example of a fictive character called "Ted" who "inhabits mobile commerce" May describes that "He is free, yet tracked; mobile, yet contained. He lives in a world that is built of a myriad decision points and whose dimensions are time, location and mission" (May, 2001). Mobile applications have to support and help the user in making spontaneous and dynamic decisions. Features that oppose or even hinder the mobile lifestyle will not be accepted.

In the process of designing and in particular marketing mobile services clear distinction should be made among early adopters and the masses of mobile phone users. Early adopters are willing to try any new product immediately. They can also be involved in product design and testing. Another scenario would be to consider them a user group with which the producer continuously exchanges information to their mutual benefit (Boutellier and Völker, 1997). They also can be a starting point for viral marketing and mouth-to-mouth propaganda. Thus, early adopters need to be involved in a different way than late adopters. For the remaining part of users, time for adoption needs to be calculated and special marketing activities need to be applied.

Mobile Products and Services: Mobile services need to provide added value within a mobile lifestyle and in mobile situations. Therefore, questions that need to be answered for each service are:

- In which form does an existing product offer mobile added value. In case of "MediAlert" the scenario of having the information available when needed in form of a personal notebook was considered more adding value than the conventional type of alert.

- How can the user find the service? A natural form for mobile users to use a service is in a spontaneous manner without planning and registering in advance. Therefore an easy to find and access option will be critical

- When there is already an existing application online, which part of the buying process can be extended to the mobile phone?

Financial Aspects: With respects to financial aspects several approaches were discussed:

- Subscription for a certain period of time

- Pay per use

- Pay per message

- Free, financed by advertising

- Free, but the service provider participates in the revenues for the transmission.

Subscription models based on a flat fee are preferred compared to per use models. Subscription models that require specific registration processes that can not be handled ad hoc with the mobile device will have much more difficulties to be accepted than those that support a spontaneous way of use. In addition subscriptions models that offer different time periods to chose might enhance the chances of the success of a model. For example, in a period when a user wants to move and is looking for a flat, he might be interested for a flat fee subscription of a "Free-Flat" alert service only for few months or even few weeks. In summary, mobile services need innovative approaches related to financial aspect of the business model.

\section{SUMMARY AND OUTLOOK}

The aim of this paper was the contribution to development of guidelines for the design of mobile services that consider user and business requirements. In order to achieve the goals a longitudal study of filed trials was set up and this paper contains a summary of the results of the first field trial. The evaluation was based on a combination of three methods: focus groups, online survey and expert in- 
terviews. The paper summarizes the results of the focus groups and aggregates them to first general guidelines for the design of mobile application.

The combination of evaluation methods has proven to be very helpful for assessing an innovative application from different perspectives. Focus groups have furthermore shown to be a highly productive method to evaluate a mobile service prototype. Further research is needed to verify and enhance the findings presented in this paper. In the future a series of field trials is planned with different applications.

\section{References}

Aalto, L; Göthlin, N.; Korhonen J.; Ojala T. (2004). Bluetooth and Wap Push Based Location-Aware Mobile Advertising System. In: Proceedings of MobiSys'04, June 6-9, 2004.

Brodt T. and Heitmann M. (2004). Product Development in Mobile Media. In: Proceedings of the Mobile and Wireless Commu nication Sumit, June, 2004.

Boutellier R. and Völker R. (1997). Erfolge durch innovative Produkte: Bausteine des Innovationsmanagements, Carl Hanser Verlag, Münche, Wien.

Churchill G. A. Jr. and Iacobucci D. (2002). Marketing Research, Methodological Foundations, 8th ed. Fort Worth, Tex. Harcourt College Publishers

Duboff R. and Spaeth J. (2000). Market Research Matters, Tools and Techniques for Aligning Your Business, John Wiley \& Sons, Inc., New York.

Flick U (2002). Qualitative Sozialforschung, Eine Einführung, Rowohlt Taschenbuch Verlag GmbH, Hamburg.

Gong, J.; Tarasewich, P. (2004). Guidelines for Handheld Mobile Device Interface Design. In: Proceedings of DSI 2004 Annual Meeting.

Gubrium J. F. and Holstein j. A. (2002). Handbook of interview research : context \& method, SAGE Publications, London.

Jarvenpaa S.L.; Lank K.R.; Takeda Y.; Tuunainen V.K. (2003). Mobile Commerce at Grossroads. In: Communication of the ACM, Vol. 46. No.12, pp. 41-44.

Kaasinen E. (2004). User Acceptance of Mobile Guides Based on Several Field Studies. In: Behavioral \& Information Technology, Vol. 24, No. 1, pp. 37-49.

Kaasinen, E (2003). User Needs for Location-Aware Mobile Services. In Personal and Ubiquitous Computing, 2003, No. 7, pp70-79.

Kasper, W.; Stanoevska-Slabeva, K.; Stavroulos, Y. (2003). “Cross-lingual Information Transformation and Summarization for Portable End-Devices with the MEMPHIS Toolbox”, In: Proceedings of the ASWN Workshop in Bern, Juli, 2003.

Krueger, R. A. (1998). Developing Questions for Focus Groups, Book 3, SAGE Publications, Thousand Oaks, pages 22-30.

May P (2001). Mobile Commerce, Opportunities, Applications, and Techonologies of Wireless Business, Cambridge University Press, Cambridge.

Reichhold A, Schierholz R, Kolbe L, Brenner W (2004): Mobile Commerce bei der Helsana: Mobile Premienerstellung. In: Wilde K, Hippner H (Eds.): Management von CRM-Projekten, Gabler, 2004.

Springer S., Beucker S., Lang C. and Bierter W. (2004). Lead User Integration, Innovation in der Internetökonomie, nova-net Konsortium, Stuttgart, available online: URL: http://novanetbscw.eproduction.iao.fhg.de/pub/bscw.cgi/d1919/Lead\%20User-Final.pdf, last accessed 15th June 2004.

Tarasevich P. (2003). Designing Mobile Commerce Applications. In: Communication of the ACM, Vol. 46. No.12, pp. 5760.

Timmers, P (1998). Business Models for Electronic Markets; In: International Journal on Electronic Markets and Business Media, Vo.8 No. 2, 1998. pp. 3-8.

Yankee Group, The (2003). Western European Mobile Data Forecast Predicts Diversifying Data Services [summary available online from: http://www.yankeegroup.com/public/home/research_showcase.jsp?ID=9270, last visited 17th June 2004] 